\title{
25 anos da revista Psicologia USP
}

\author{
Zelia Ramozzi-Chiarottino \\ Fundadora da Revista em 1990
}

Resumo: Este pequeno artigo narra a fundação da revista Psicologia USP em 1990 e sua origem, inspirada no Jornal Brasileiro de Psicologia. Faz também, singela homenagem ao seu idealizador Professor Norberto de Abreu e Silva Neto.

Palavras-chave: revista Psicologia USP. História do IP-USP. Jornal Brasileiro de Psicologia. pre bom.

O tempo não volta... mas relembrar a história é sem-

Recordemo-nos de que foi com ideais claros que a Psicologia USP foi lançada em 1990, durante nossa gestão como Diretora do Instituto de Psicologia da Universidade de São Paulo (IPUSP). Quem nos escolheu para exercermos essa função durante quatro anos foi o renomado físico brasileiro José Goldemberg, então Reitor da Universidade de São Paulo; a ele nosso perene reconhecimento.

A idéia de fazer uma revista do IP-USP surgiu com o Prof. Norberto Abreu e Silva Neto, recente e prematuramente falecido e a quem rendemos nossa homenagem pelo que realizou em nossa Faculdade e na Universidade de Brasília-UnB; e por ter levado o nome dessas Instituições para fora de nosso país, com raro brilho. Destacamos aqui seu papel no Centro Wittgenstein de Graz, na Austria, sobretudo quando este esteve sob a direção do pensador Rufolf Haller.

Norberto de Abreu e Silva Neto, por volta de 1984, teve a ideia de criar a revista Psicologia USP e recebeu apoio incondicional de seu colega Prof. Antonio Paschoal Agatti. Com muito esforço e dedicação reuniram colegas para realizarem a empreitada.

Quando assumimos a Diretoria da Instituição, (1988) faltavam ainda as diretrizes que em nosso entender deveriam servir de base a um jornal ou revista, sobretudo científica.

Apesar de estarmos, em 1964/1967, cursando a PósGradução em Filosofia das Ciências em Aix-en-Provence, (França), tomáramos conhecimento dos propósitos e das dificuldades de Annita de Castilho e Marcondes Cabral para fundar o Jornal Brasileiro de Psicologia, em 1964, ainda na Cadeira de Psicologia do Departamento de Filosofia da Faculdade de Filosofia, Ciências e Letras (FFCL). Foi este Jornal que nos inspirou.

Seu primeiro volume e primeiro número, publicado em janeiro daquele ano, participava, então, de um novo momento da Psicologia no Brasil, ou seja, o da criação da profissão de Psicólogo. Esse Jornal viera substituir o Boletim da Faculdade de Filosofia da Universidade de São Paulo, - Cadeira de Psicologia, cujo número 1, [que

* Endereço para correspondência: zramozzi@yahoo.com.br era já o LXXV da Faculdade de Filosofia como um todo] veio à luz em 1946, com a obra "Introdução à Psicologia Social", de Otto Klineberg, Professor Convidado da Cadeira de Psicologia do Departamento de Filosofia da Faculdade de Filosofia, cujo Diretor era André Dreyfus, sendo Reitor da USP, o ilustre e inesquecível médico-cirurgião, Benedicto Montenegro, ex-Diretor da Faculdade de Medicina.

$\mathrm{Na}$ "Apresentação" do Jornal Brasileiro de Psicologia, sua fundadora já dizia, na década de 60, que uma revista que se pretende científica não pode isolar-se, ao contrário, objetiva ser um meio de inserção de uma possível contribuição brasileira à psicologia internacional; "não apenas recebendo artigos de pesquisadores de outras terras", mas também produzindo coisas novas.

De acordo com essas premissas, nossa primeira ideia enquanto editora da Psicologia USP, foi então a de que suas publicações não seriam apenas em português, aceitaríamos textos em francês, inglês e espanhol, no sentido de abrir caminho para uma futura revista internacional, mas que congregasse temas de especialistas- pesquisadores de nossos quatro Departamentos. Convidamos para formar o Editorial, Advisory Board, além de alguns de nossos colegas, pesquisadores de outras unidades da USP, de outros países, França e Argentina, por exemplo; e de outras universidades brasileiras, tais como Federal do Rio de Janeiro e Pontifícia Universidade Católica de São Paulo.

Na época da criação do Jornal Brasileiro de Psicologia, Annita já entendia que uma revista científica de um campo ainda novo, como o da Psicologia, precisava reunir trabalhos que constituíssem seu núcleo e que demonstrasse, também, sua inserção no campo da ciência contemporânea.

Sua fundadora, ao lado da Diretora adjunta do Jornal (Carolina Martuscelli Bori) e de seus demais assistentes, organizam um primeiro número da revista, que fala dos temas que iniciariam a formação da nova área de conhecimento na USP, enquanto ciência e profissão, embora somente quatro anos mais tarde fosse criado o Instituto de Psicologia.

Assim, lemos, no primeiro volume do Jornal Brasileiro de Psicologia, interessante e significativa 
"Apresentação" na qual diz a Professora Annita de Castilho e Marcondes Cabral:

Por acreditarmos que corresponde a uma exigência do desenvolvimento da psicologia, nos animamos a enfrentar as dificuldades de uma empresa tão sedutora quanto árdua como a de publicar uma revista científica.

A recente lei que regulamentou a profissão de psicólogo e instituiu um currículo universitário como fundamento de seu status de profissão liberal, marcou o início de uma nova fase da psicologia no Brasil e veio requerer medidas para a intercomunicação e integração dos núcleos dispersos, os quais, em grande parte, mutuamente se desconhecem.
O JORNAL BRASILEIRO DE PSICOLOGIA visa a contribuir para essa comunicação entre aqueles que trabalham no campo da psicologia e, assim, a uma integração de seus esforços - condições, por sua vez, para que o desenvolvimento efetivo da ciência e da profissão acompanhe o passo das conquistas na esfera legal.

Por isso, esta não será uma revista exclusivamente técnica ao molde das revistas altamente especializadas norte-americanas ou europeias.

Porque o queremos sensível ao momento e também noticioso, chamamo-lo JORNAL. (Cabral, 1964a, p. 3)

Já no primeiro número temos os artigos:

No 1 - O Mito do Cordeiro que Bale: Alguns Pensamentos Acerca de Imagens e Palavras - Rudolf Arnheim. (tradução de Arno Engelmann de uma conferência do autor, por ele assistida no Darmouth College, (novembro de 1962) em Hanover, por ocasião da inauguração do Hopkins Art Center, desta Universidade, onde fazia seus estudos de pós - licenciatura.)

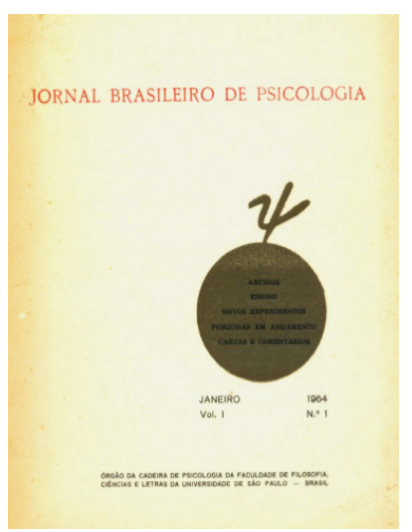

№ 2 - O Cânon de Lloyd Morgan e a Psicologia Comparada - Walter Hugo de Andrade Cunha.

№3 - Técnicas de Linha Base Comportamental - J. Guilmour Sherman.

No4 - O Efeito da Atmosfera - Rodolpho Azzi.

№ 5 - Aparelhos e o Laboratório de Psicologia - Carolina Martuscelli Bori.

$\mathrm{N}^{0} 6$ - Distúrbios Psiconeurológicos da Conduta Infantil e Perturbações do Esquema Corporal - Haim Grunspum.

No 7 - Estudo sobre Aprendizagem e Extinção de uma Discriminação em Apis Mellifera - Isaias Pessotti.

Seç̧ões:

SOBRE ENSINO (Dante Moreira Leite).

NOVOS EXPERIMENTOS (Rodolpho Azzi).

PESQUISAS EM ANDAMENTO

(Carolina Martuscelli Bori).

CARTAS E COMENTÁRIOS

(Maria Margarida Andrade).

PÁGINA DOS ALUNOS

(Regina Chnaiderman).

RESENHAS (Maria Helena C. F. Steiner).
NOTICIÁRIO (Arno Engelmann).

Capa: Iaroslau Dedina.

Pretendíamos comentar apenas o primeiro volume, número 1 , mas não podemos deixar de lembrar que ainda nele, em seu número 2 aparece, como artigo, a significativa homenagem que Annita de Castilho e Marcondes Cabral presta a Nilton Campos (1898-1963) na XVI Reunião Anual da Sociedade Brasileira para o Progresso da Ciência (SBPC) que se realizou em Ribeirão Preto, 1964 (Cabral, 1964b), como o médicopsicólogo, psiquiatra e filósofo da ciência, catedrático da Faculdade Nacional de Filosofia, no Rio de Janeiro, como um dos primeiros brasileiros realmente dedicados à Psicologia entendida como ciência. 


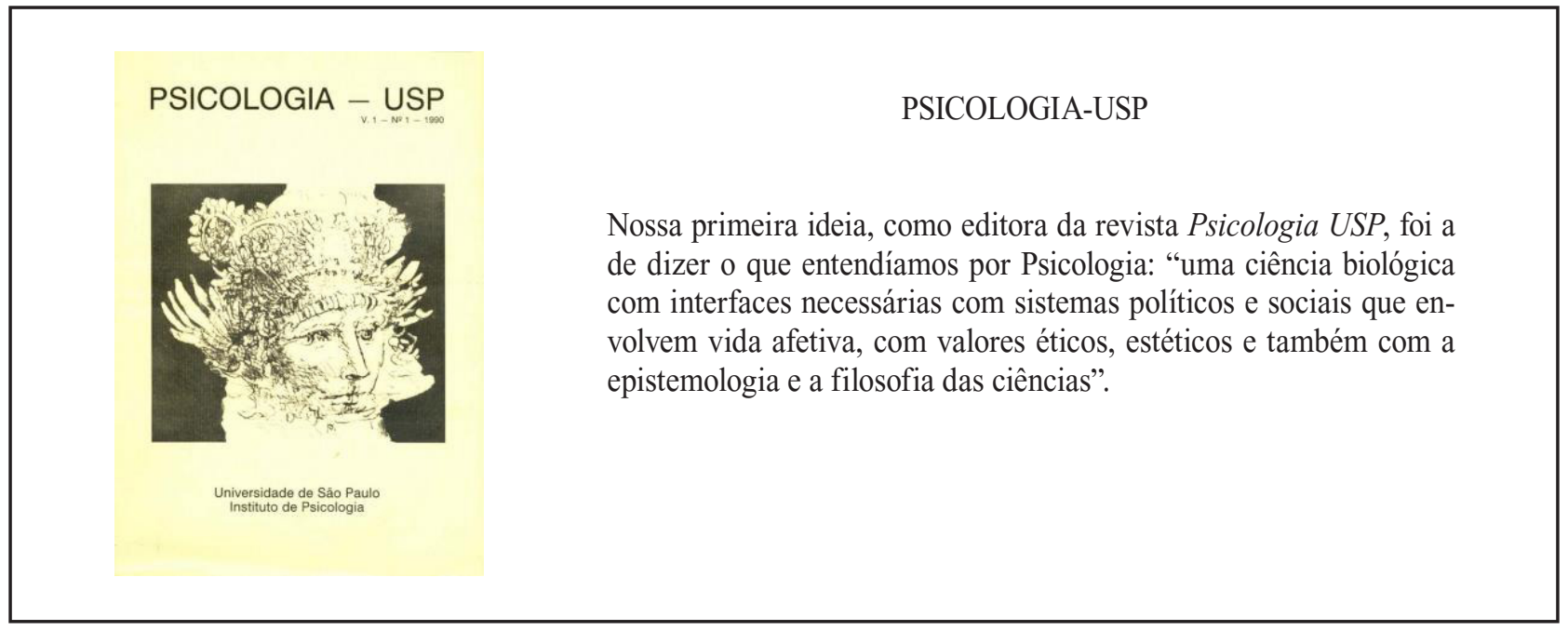

A partir daí, com o auxílio do Conselho de Redação, (Elsa Gonçalves Antunha, Elza Corrêa Granja, João Augusto Frayze-Pereira, Leonidas Hegenberg, Maria Regina de Souza Godeli e Norberto Abreu e Silva Neto) construiríamos nossa Revista do IPUSP.

A revista teria um "estilo" e sabemos que os componentes do estilo de um sistema variam com o referencial teórico, como ouvimos tantas vezes nas aulas de nosso Mestre e orientador Gilles Gaston Granger, não é uma questão apenas estética.

Nosso estilo pretendido foi então, o de reunir na Psicologia USP, as várias áreas e tendências da Psicologia atual. Nossos números publicados confirmam esse ideal: os temas incluem questões complexas de linguagem, ética, estética, religião, assim como pesquisas empíricas, por exemplo, longa investigação, quatro anos, com crianças surdas, pesquisas sobre o sorriso da criança, estimulação precoce e de outro lado, reflexões sobre Psicanálise, Psicoterapia Breve, Escola de Frankfurt, Modelos teóricos em Psicologia, Psicologia da Religião, Epistemologia Genética, etc.

Revendo os poucos volumes editados em nossa gestão, orgulhamo-nos deles. Grandes professores de reputação internacional aí escreveram em suas próprias línguas ou ofereceram seus trabalhos para serem comentados e ou traduzidos: Jean-Marie Dolle, (Université Lumière, Lyon II), Jacques Vonèche, (Université de Genève), Rudolf Haller, (Karl Franzens Universität Graz, Austria), Haulf Hübner (Presidente da Österreichische Ludwig Wittgenstein Gesellschaft), Jorge Visca, (Universidad de Buenos Aires), Maria Alicia Ferrari de Zamorano, (Universidad de Buenos Aires), são exemplos. Ora, dirão alguns, Norberto Abreu e Silva Neto estagiou no Centro Wittgenstein de Graz (Austria) e no Centro de Documentação de Filosofia Austríaca, no mesmo país e então trouxe esses pesquisadores austríacos para eventos na USP e seus artigos para a revista Psicologia USP, o mesmo aconteceu com a Editora da Revista que estudou na França e na Suíça e teve como orientanda uma argentina... "assim é fácil", acreditaram alguns. Perguntamos agora: e não era esse o verdadeiro intercâmbio cultural internacional almejado pela Professora Annita, quando apresenta o seu Jornal Brasileiro de Psicologia, acima citado? É preciso que se diga que esse foi apenas o início do intercâmbio que persiste até hoje. Nós também, da Universidade de São Paulo (Norberto Abreu e Silva Neto, mais tarde, da Universidade de Brasília), passamos a colaborar com eles com publicações de livros e artigos, na França, na Suíça, na Áustria, na Argentina, etc. Portanto, a colaboração foi recíproca e duradoura. Essa foi também, uma das formas por intermédio das quais alguns de nossos colegas que não tinham podido trabalhar em universidades estrangeiras, iniciaram trocas intelectuais com grandes pesquisadores do exterior.

Foi a partir do intercâmbio já citado que o IP, graças a Norberto Abreu e Silva Neto, participou da Comemoração do Primeiro centenário de Wittgenstein, 1989, sob a presidência do Professor convidado Rudolf Haller, realizada pelo IEA, na Reitoria da USP. O Instituto de Psicologia fez sucesso nessa homenagem a Ludwig Wittgenstein com sua participação nos campos da Linguagem, Ética e Lógica da obra do grande filósofo.

Diga-se de passagem, que Norberto, chegou a ser considerado um dos grandes especialistas do mundo na obra de Wittgenstein, com muitas publicações relevantes sobre o tema, em grandes revistas do exterior.

Além dos colaboradores de fora do país e já acima citados, escreveram também, na Psicologia USP, professores de todos os nossos departamentos, outros de fora do Instituto e de várias linhas de pesquisa: experimental, clínica, aprendizagem, personalidade, social etc. Assim tivemos artigos teóricos, relatos de pesquisa e reflexões sobre a própria Psicologia. Os autores foram: Ana Maria Almeida Carvalho, Aidyl Queiroz Perez Ramos, Cesar Ades, Eduardo Coin de Carvalho, Edwiges de Matos Silvares, Elisabeth Becker, Emma Otta, Fernando Becker, Geraldo José de Paiva, Geraldina Porto Witter, Iray Carone, Jerusa Vieira Gomes, João Augusto Frayze-Pereira, João Eduardo Coin de Carvalho, José Leon Crochik, Juan Perez Ramos, 
Leonidas Hegenberg, Lino de Macedo, Maria Julia Kovacs, Maria Lucia Amiralian, Marina Plastina Buzzo, Nicolau Tadeu Arcaro, Norberto Abreu e Silva Neto, Nielsy Puglia Bergamasco, Rachel Rodrigues Kerbauy, Ryad Simon, Ronilda Ribeiro, Rosane Gabriele de Melo, Simone Sarra, Suely Damergian, Tania Aiello Tsu, Valdenir Tofolo e a editora, com um único artigo de três páginas.

Hoje consideramos que essa revista nasceu em berço de ouro para um país em desenvolvimento. Muito cedo, 1992, quando terminamos nosso mandato na Direção do Instituto fomos convidada, pela nova Direção, a deixar também a função de Editora. Deixamo-la com tristeza, mas com a certeza do dever cumprido.

Nós e o grupo com o qual iniciamos a árdua tarefa de criar a Psicologia USP tivemos singela satisfação: seu símbolo (dessa vez, puramente estético) que escolhemos para a revista que ilustrou sua capa, a gravura de Marcelo Grasmann, esse continuou, mesmo quando se tornou impressa. Obter essa obra de arte, para ilustrar nossa capa foi mérito de Elza Antunha e João Augusto Frayze-Pereira por tê-la imaginado e conseguido. Procuraram Grasmann que ficou muito feliz (com a modéstia do grande artista) em ceder sua gravura para ilustrar a capa da revista e presenteou-nos com outra gravura que enfeita sempre nossa casa. Até hoje somos muito gratos a Marcelo Grasmann por sua generosidade.

Obrigada Angélica Sabadini pelo convite que nos fez para escrevermos essas linhas.

Parabéns à Psicologia USP por ter sobrevivido e evoluído, até chegar aos seus 25 anos.

Quando a revista fez 20 anos, escrevemos: "Queremos augurar que brevemente passe a ser esta, uma revista pelo menos bilíngue, hoje, português/inglês, para que se torne inserida no mundo da ciência, lida e reconhecida em vários países. Já temos no Brasil exemplos bem sucedidos dessa iniciativa. O bilinguismo é necessário, mas não suficiente para alcançar esse fim, sabemos todos, mas esperemos que as novas e profícuas trocas intelectuais, inclusive com pesquisadores estrangeiros, assim como as já de há muito existentes aqui, apareçam retratadas no âmbito da Psicologia USP. São os nossos votos.“

Hoje, cinco anos depois, vemos nossos votos alcançados: a revista é on line e bilíngue. Parabéns àqueles que deram esse passo de gigante: Ana Maria Loffredo, Gustavo Martineli Massola, Aparecida Angélica Z. P. Sabadini e Comissão Executiva da revista.

\section{Twenty five years of Psicologia USP journal}

Abstract: This short article is on the establishement of the Psicologia USP journal and its origins, which was inspired by the journal Jornal Brasileiro de Psicologia. It also renders a tribute to Doctor Norberto de Abreu e Silva Neto, the creator of the journal.

Keywords: journal Psicologia USP. History of IP-USP. Jornal Brasileiro de Psicologia.

\section{Les 25 ans de la revue Psicologia USP}

Résumé: Ce petit article raconte l'origine de la revue Psicologia USP, inspirée de la revue Jornal Brasileiro de Psicologia. II rend aussi un hommage au Professeur Norberto de Abreu e Silva Neto, le créateur de La revue.

Mots-clés: revue Psicologia USP. Histoire de I'IP-USP. Jornal Brasileiro de Psicologia.

\section{Años de la revista Psicologia USP}

Resumen: Este breve articulo narra la fundación de la revista Psicologia USP em 1990, asi como también su origen inspirado em revista Jornal Brasileiro de Psicologia. Hace además, um singular homenaje póstumo a su realizador Professor Norberto de Abreu e Silva Neto.

Palabras clave: revista Psicologia USP. Historia del IP-USP. Jornal Brasileiro de Psicologia.

\section{Referências}

Cabral, A. de C. e M. (1964a). Apresentação. Jornal Brasileiro de Psicologia, 1(1), 3-4.
Cabral, A. de C. e M. (1964b). Nilton Campos (1898-1963). Jornal Brasileiro de Psicologia, 1(2), 3-12. 